\title{
Structure of Aldoses Condensation Products with 2-Hydroxy- and 2-Aminobenzohydrazides
}

\author{
Igor V. Lagoda1, Andrei Yu Ershov'², Stanislav I. Yakimovich³, Marina Yu Vasileva², \\ Valery A. Polukeev³, Ludmila Yu Kuleshova4, Irina S. Korovina², Valery V. Shamanin² \\ ${ }^{1}$ Scientific Research Test Center (Medical and Biological Protection), Institute of Military Medicine, Saint \\ Petersburg, Russia \\ ${ }^{2}$ Institute of Macromolecular Compounds, Russian Academy of Sciences, Saint Petersburg, Russia \\ ${ }^{3}$ Saint Petersburg State University, Saint Petersburg, Russia \\ ${ }^{4}$ I.P.Pavlov Ryazan State Medical University, Ryazan, Russia \\ Email: ${ }^{\prime}$ lagodai@mail.ru
}

Received 15 April 2016; accepted 30 April 2016; published 4 May 2016

Copyright (C) 2016 by authors and OALib.

This work is licensed under the Creative Commons Attribution International License (CC BY).

http://creativecommons.org/licenses/by/4.0/

(c) (i) Open Access

\begin{abstract}
The structure of the condensation products of 2-hydroxybenzohydrazide, 2-aminobenzohydrazide, and N-methyl-N-(2-aminobenzo) hydrazide with a series of aldoses (L-arabinose, D-ribose, Lrhamnose, D-galactose, D-glucose, and D-mannose) was studied by ${ }^{1} \mathrm{H}$ - and ${ }^{13} \mathrm{C}$-NMR spectroscopy. The condensation products of aldoses with 2-hydroxybenzohydrazide and 2-aminobenzohydrazide in DMSOd $_{6}$ solutions exist as equilibrium mixtures of linear acylhydrazone and cyclic pyranose and furanose forms. The aldoses condensation products with $\mathrm{N}$-methyl-N-(2-aminobenzo)hydrazide in the crystalline state and in $\mathrm{DMSOd}_{6}$ solutions have cyclic benzo-1,2,4-triazepin structure.
\end{abstract}

\section{Keywords}

Aldoses 2-Hydroxy- and 2-Aminobenzohydrazides, Benzo-1,2,4-Triazepines, Ring-Chain-Ring Tautomerism

Subject Areas: Organic Chemistry

\section{Introduction}

Condensation products of aldoses with acylhydrazines and their derivatives have been reported to possess sig-

${ }^{*}$ Corresponding author.

How to cite this paper: Lagoda, I.V., Ershov, A.Y., Yakimovich, S.I., Vasileva, M.Y., Polukeev, V.A., Kuleshova, L.Y., Korovina, I.S. and Shamanin, V.V. (2016) Structure of Aldoses Condensation Products with 2-Hy-droxy- and 2-Aminobenzohydrazides. Open Access Library Journal, 3: e2636. http://dx.doi.org/10.4236/oalib.1102636 
nificant activity as antimicrobial, antifungal [1], and anti-HIV [2] agents. Among aldoses acylhydrazones containing in their structure a functional 2-hydroxybenzoyl and 2-aminobenzoyl group is known only 2-hydroxybenzoylhydrazones of arabinose, glucose and mannose [3], the structure of which is not proved. The presence of a functional nucleophilic $\mathrm{NH}_{2}$-group in the aldosohydrazone fragment could give rise in appearance of new structural possibilities in further transformations. Intermolecular nucleophilic attacks of $\mathrm{NH}_{2}$-fragments at the $\mathrm{C}=\mathrm{N}$ polar bond contained in the linear structure can lead to repeated cyclization with the formation of new cyclic forms. Condensation products of N-methyl-N-(2-aminobenzo) hydrazide with monocarbonyl compounds tend to undergo intramolecular cyclization via nucleophilic addition of the $\mathrm{NH}_{2}$-group at the $\mathrm{C}=\mathrm{N}$ bond with formation of seven-membered benzo-1,2,4-triazepin ring [4] [5]. In some cases, this process is reversible, so that equilibrium mixture of linear hydrazone and cyclic benzotriazepin tautomer may exist in solution.

The aim of the present work was to study of the structure of the condensation products of aldoses with hydrazides of 2-hydroxybenzoic (2- $\left.\mathrm{HOC}_{6} \mathrm{H}_{4} \mathrm{CONHNH}_{2}\right)$, 2-aminobenzoic $\left(2-\mathrm{H}_{2} \mathrm{NC}_{6} \mathrm{H}_{4} \mathrm{CONHNH}_{2}\right)$, and N-methyl$\mathrm{N}$-2-aminobenzoic $\left(2-\mathrm{H}_{2} \mathrm{NC}_{6} \mathrm{H}_{4} \mathrm{CONMeNH} \mathrm{H}_{2}\right)$ acids by ${ }^{1} \mathrm{H}$ - and ${ }^{13} \mathrm{C}$-NMR spectroscopy methods.

\section{Results and Discussion}

Compounds 1a-1j and 2a-2d were synthesized in yields $55 \%-90 \%$ by heating equimolar amounts of the corresponding aldose (L-arabinose, D-ribose, L-rhamnose, D-galactose, D-glucose, D-mannose) and corresponding acylhydrazine: 2-hydroxybenzohydrazide, 2-aminobenzohydrazide, and N-methyl-N-(2-aminobenzo) hydrazide in boiling methanol for a period of $1-3 \mathrm{~h}$ (Figure 1, Figure 2 and Table 1).

In all experiments, the ${ }^{1} \mathrm{H}$ - and ${ }^{13} \mathrm{C}-\mathrm{NMR}$ spectra were recorded at definite time intervals starting from the moment of dissolution until the end of transformations. In addition, the structure of the compounds under study in the crystalline state was confirmed by solid-phase high-resolution ${ }^{13} \mathrm{C}-\mathrm{NMR}$ spectroscopy (CPMAS). For example, pyranose form $\mathbf{B}$ was expected to give a signal from the anomeric C-1 atom at $\delta 85-90 \mathrm{ppm}$; analogous signal from five-membered furanose tautomer $\mathbf{C}$ is located at $\delta 95-100 \mathrm{ppm}$ [6] [7]. The C-1 signal of possible benzo-1,2,4-triazepin tautomer $\mathbf{D}$ should appear in a stronger field, at $\delta 70-75 \mathrm{ppm}$, which is typical of $\mathrm{sp}^{3}$-hybridized carbon atom in seven-membered ring, located between two nitrogen atoms [4] [5]. Hydrazone structure A should give rise to a downfield signal at $\delta 145-155 \mathrm{ppm}(\mathrm{C}=\mathrm{N})$ in the ${ }^{13} \mathrm{C}-\mathrm{NMR}$ spectrum. The formation of analogous seven-membered cyclic benzo-1,3,4-oxadiazepin tautomers for 2-hydroxybenzohydrazones 1a-1f via attack by the $\mathrm{OH}$ group on the $\mathrm{C}=\mathrm{N}$ bond should be ruled out. It is known that condensation products<smiles>[Y]c1ccccc1C(=O)NNC1(C)O[C@H]([R])[C@@H](O)[C@H](O)[C@H]1O</smiles>

B $1 \mathrm{a}-1 \mathrm{j}$<smiles>[Y]c1ccccc1C(=O)N/N=C/C(O)C(O)C(O)C([R])O</smiles>

A $1 \mathrm{a}-1 \mathrm{j}$<smiles>[Y]c1ccccc1C(=O)NN([TlH])[C@@H]1O[C@H](C([R])O)[C@@H](O)[C@H]1O</smiles>

C 1a-1j

Figure 1. Aldoses 2-hydroxy- and 2-aminobenzoyl hydrazones 1a-1j.<smiles>[R]C1O[C@H](NN(C)C(=O)c2ccccc2N)[C@H](O)C(O)C1O</smiles>

B 2a-2d<smiles>[R]C(O)C(O)C(O)C(O)/C=N/N(C)C(=O)c1ccccc1N</smiles>

A 2a-2d<smiles>[R]C(O)C(O)[C@H](O)[C@H](O)C1=NN(C)C(=O)c2ccccc2N1</smiles>

D 2a-2d 
Table 1. Tautomeric composition of the aldoses 2-hydroxy- and 2-aminobenzoyl hydrazones $\mathbf{1 a - 1 j}$ (72 $\mathbf{h}$ after dissolution).

\begin{tabular}{|c|c|c|c|c|c|c|c|}
\hline \multirow{2}{*}{ Compound } & \multirow{2}{*}{$\mathrm{X}$} & \multirow{2}{*}{$\mathrm{R}$} & \multirow{2}{*}{ Initial aldose } & \multirow{2}{*}{$\begin{array}{l}\text { Form in } \\
\text { crystals }\end{array}$} & \multicolumn{3}{|c|}{ Tautomeric composition (\%) in DMSO $d_{6}$} \\
\hline & & & & & Form B & Form $\mathbf{A}$ & Form $\mathbf{C}$ \\
\hline 1a & $\mathrm{O}$ & $\mathrm{H}$ & L-Arabinose & B & 45 & 30 & 25 \\
\hline $1 \mathbf{b}$ & $\mathrm{O}$ & $\mathrm{H}$ & D-Ribose & B & 50 & 40 & 10 \\
\hline $1 \mathrm{c}$ & $\mathrm{O}$ & $\mathrm{CH}_{3}$ & L-Rhamnose & B & 80 & 20 & - \\
\hline 1d & $\mathrm{O}$ & $\mathrm{CH}_{2} \mathrm{OH}$ & D-Galactose & B & 70 & 30 & - \\
\hline $1 \mathrm{e}$ & $\mathrm{O}$ & $\mathrm{CH}_{2} \mathrm{OH}$ & D-Glucose & B & 95 & 5 & - \\
\hline 1f & $\mathrm{O}$ & $\mathrm{CH}_{2} \mathrm{OH}$ & D-Mannose & B & 35 & 65 & - \\
\hline $1 \mathrm{~g}$ & $\mathrm{NH}$ & $\mathrm{H}$ & L-Arabinose & B & 65 & 25 & 10 \\
\hline $1 \mathrm{~h}$ & $\mathrm{NH}$ & $\mathrm{H}$ & D-Ribose & A & 25 & 60 & 15 \\
\hline $1 \mathrm{i}$ & $\mathrm{NH}$ & $\mathrm{CH}_{2} \mathrm{OH}$ & D-Glucose & B & 100 & - & - \\
\hline $1 \mathrm{j}$ & $\mathrm{NH}$ & $\mathrm{CH}_{2} \mathrm{OH}$ & D-Mannose & B & 100 & - & - \\
\hline
\end{tabular}

of 2-hydroxybenzohydrazide with aldehydes and ketones have exclusively linear structure and they do not tend to undergo the above cyclization [8].

The ${ }^{1} \mathrm{H}$ - and ${ }^{13} \mathrm{C}$-NMR spectra of the condensation product of 2-hydroxybenzoic acid hydrazide with L-arabinose 1a, recorded in $\mathrm{DMSO} d_{6}$ immediately after dissolution, contained one set of signals corresponding to cyclic pyranose structure B. It is characterized by two downfield singlets at $\delta 10.22$ and $12.20 \mathrm{ppm}$ in the ${ }^{1} \mathrm{H}-$ NMR spectrum from protons in the NHCO group and phenolic $\mathrm{OH}$ group, respectively, and the $\mathrm{sp}^{3}$-hybridized $\mathrm{C}-1$ atom gives a signal at $\delta 90.80 \mathrm{ppm}$ in the ${ }^{13} \mathrm{C}$-NMR spectrum. Taking into account that the ${ }^{1} \mathrm{H}$ - and ${ }^{13} \mathrm{C}$-NMR spectra were recorded immediately after dissolution, i.e., possible tautomeric and configurational transformations had no time to occur, we presumed that the observed spectral parameters reflect the structure of compound 1a in the crystalline state. The ${ }^{1} \mathrm{H}-$ and ${ }^{13} \mathrm{C}-\mathrm{NMR}$ spectra of $\mathbf{1 a}$ changed with time, and signals assignable to the second stereoisomer of six-membered structure $\mathbf{A}$, as well as to linear tautomer $\mathbf{A}$ and furanose structure $\mathbf{C}$, appeared. Structure $\mathbf{A}$ is characterized by a doublet at $\delta 7.74 \mathrm{ppm}$ in the ${ }^{1} \mathrm{H}-\mathrm{NMR}$ spectrum from the $\mathrm{N}=\mathrm{CH}$ azomethine proton and a signal at $\delta 155.05 \mathrm{ppm}(\mathrm{C}=\mathrm{N})$ in the ${ }^{13} \mathrm{C}-\mathrm{NMR}$ spectrum. The presence of five-membered furanose tautomer $\mathbf{C}$ in a solution of $\mathbf{1 a}$ in $\mathrm{DMSO} d_{6}$ follows from the presence of signals at $\delta$ $84.63(\mathrm{C}-4)$ and $95.55 \mathrm{ppm}(\mathrm{C}-1)$ in the ${ }^{13} \mathrm{C}-\mathrm{NMR}$ spectrum. After some time, the NMR spectra of compound 1a no longer changed, indicating establishment of ring-chain-ring equilibrium. The equilibrium tautomer mixture consists of $45 \%$ of pyranose tautomer $\mathbf{B}, 30 \%$ of linear structure A, and $25 \%$ of furanose form $\mathbf{C}$ (Table 1 ).

Analogous pattern was observed for a solution of compound $\mathbf{1 b}$ (condensation product of 2-hydroxybenzohydrazide and D-ribose) in $\mathrm{DMSO}_{6}$; the fractions of structures $\mathbf{A}, \mathbf{B}$, and $\mathbf{C}$ in the equilibrium tautomer mixture of $\mathbf{1 b}$ differ insignificantly from those found for compound 1a. Unlike arabinose and ribose derivatives $\mathbf{1 a}$ and $\mathbf{1 b}$, the condensation products 1c-1f derived from 2-hydroxybenzohydrazide and hexoses do not give rise to cyclic furanose form $\mathbf{C}$. Compounds $\mathbf{1 c - 1 f}$ in the crystalline state have cyclic structure B. The cyclic pyranose structure of crystalline compound 1e (condensation product of 2-hydroxybenzohydrazide with glucose) was confirmed by its solid-phase ${ }^{13} \mathrm{C}-\mathrm{NMR}$ spectrum. In going to solutions in $\mathrm{DMSO} d_{6}$, compounds $\mathbf{1 c}$-1f undergo partial transformation into linear hydrazone tautomer A. Insofar as the fraction of the linear tautomer for all the examined condensation products of 2-hydroxybenzohydrazide with aldoses did not exceed $30 \%-40 \%$, the term "2-hydroxybenzoyl hydrazone" should be regarded as arbitrary as applied to such systems.

A single set of signals corresponding to cyclic pyranose form $\mathbf{B}$ is observed for the condensation product of 2-aminobenzohydrazide with L-arabinose $\mathbf{1 g}$ immediately after dissolution. As in the case of compound 1a, we may assume that the spectral data reflect the structure of compound $\mathbf{1 g}$ in the crystalline state. Sets of signals corresponding both to the five-membered furanose form $\mathbf{C}$ and linear aldosohydrazone form $\mathbf{A}$ gradually arise in the ${ }^{13} \mathrm{C}$-NMR spectrum in $\mathrm{DMSO} d_{6}$. The ${ }^{13} \mathrm{C}$-NMR signal at $\delta 151.35 \mathrm{ppm}$ for the $\mathrm{C}=\mathrm{N}$ carbon is characteristic for linear form $\mathbf{A}$ (Table 1). One set of signals belonging to linear form $\mathbf{A}$ is observed in the ${ }^{13} \mathrm{C}$ NMR spectrum of the 2-aminobenzohydrazide condensation product with ribose $\mathbf{1 h}$ taken immediately after dissolution. This finding suggests that compound $\mathbf{1 h}$ has the same structure in the crystalline state. After 2 days, sets of signals 
arise corresponding to the cyclic pyranose form $\mathbf{B}$ and furanose form $\mathbf{C}$ in the ${ }^{13} \mathrm{C}$-NMR spectrum of the solution. The ${ }^{13} \mathrm{C}$-NMR signal for atom $\mathrm{C}-1$ at $\delta 88.13 \mathrm{ppm}$ is characteristic for form $\mathbf{C}$. The presence of the five-membered furanose form $\mathbf{C}$ in ${ }^{13} \mathrm{C}$-NMR spectra of compounds $\mathbf{1 g}, \mathbf{1 h}$ is indicated by the signals for C-4 and C- 1 at $\delta$ 83 and 95 ppm, respectively. The spectrum of compound $\mathbf{1 h}$ stops changing after some time, indicating the establishment of a ring-chain equilibrium in which linear form A $(60 \%)$ exists along with the cyclic pyranose $\mathbf{B}$ $(25 \%)$ and furanose $\mathbf{C}$ forms (15\%).

Thus, in contrast to the results of a study of El-Barbary et al. [1] on the structure of a series of 3,5-disubstituted 2-aminobenzohydrazones of aldoses, in which the linear aldosohydrazone structure was adopted, we have shown that in the case of aldose 2-aminobenzoylhydrazones $\mathbf{1 g}, \mathbf{1 h}$, these compounds may convert to alternative cyclic pyranose and furanose forms, as well as both ring-chain and ring-linear-ring tautomeric equilibria are possible.

Going from arabinose derivative $\mathbf{1 g}$ and ribose derivative $\mathbf{1 h}$ to products of condensation with hexoses $\mathbf{1 i}, \mathbf{1} \mathbf{j}$ is accompanied by disappearance of the cyclic furanose form $\mathbf{C}$ and linear aldosohydrazone form $\mathbf{A}$ from the equilibrium. In the crystalline state compounds $\mathbf{1 i}, \mathbf{1} \mathbf{j}$ have pyranose structure $\mathbf{B}$, while the ${ }^{13} \mathrm{C}-\mathrm{NMR}$ spectra indicate that these compounds in $\mathrm{DMSO}_{6}$ solution are represented by geometric $\alpha, \beta$-isomers of this form.

Different behavior is found for compounds $\mathbf{2 a - 2 d}$, which are the products of the condensation of aldoses with $\mathrm{N}$-methyl-N-(2-aminobenzo)hydrazide (Figure 2). The change in the ${ }^{13} \mathrm{C}-\mathrm{NMR}$ spectra of all these products indicates that they have the cyclic benzo-1,2,4-triazepin structure $\mathbf{D}$ in the crystalline state. The ${ }^{13} \mathrm{C}-\mathrm{NMR}$ signal for atom $\mathrm{C}-1$ at $\delta 75-80 \mathrm{ppm}$ characteristic for $\mathrm{sp}^{3}$-hybridized carbon atom in a seven-membered ring attached to two nitrogen atoms [4] [5] is diagnostic for benzo-1,2,4-triazepin form D. Signals corresponding to a second configurational isomer of the benzo-1,2,4-triazepin form $\mathbf{D}$ ' are found in the ${ }^{1} \mathrm{H}$ - and ${ }^{13} \mathrm{C}$-NMR spectra of compounds 2a-2d in $\mathrm{DMSO} d_{6}$. It was impossible to determine the $2 R$ - or $2 S$-configuration of these derivatives. The ${ }^{1} \mathrm{H}$ - and ${ }^{13} \mathrm{C}$-NMR spectra of solutions of the aldoses condensation products with $\mathrm{N}$-methyl-N-(2-aminobenzo)hydrazide stop changing after 4 - 7 days, indicating that transition to the possible linear form $\mathbf{A}$ and cyclic pyranose form $\mathbf{B}$ does not occur. A tendency to cyclize with formation of a seven-membered benzo-1,2,4-triazepin ring through attack of the nitrogen atom at the $\mathrm{C}=\mathrm{N}$ bond is a common feature of compounds $\mathbf{2 a - 2 d}$.

\section{Conclusion}

The ability to undergo ring-chain or ring-chain-ring tautomeric transformation involving two different cyclic structures was found for the aldoses condensation products with 2-hydroxy- and 2-aminobenzohydrazides. The aldoses condensation products with N-methyl-N-(2-aminobenzo) hydrazide were found to strongly tend to form seven-membered benzo-1,2,4-triazepin form via intramolecular nucleophilic addition of the $\mathrm{NH}_{2}$ group at the hydrazone $\mathrm{C}=\mathrm{N}$ bond.

\section{Experimental Part}

${ }^{1} \mathrm{H}$ - and ${ }^{13} \mathrm{C}-\mathrm{NMR}$ spectra in $\mathrm{DMSO} d_{6}$ were registered on a spectrometer Bruker AV-400 at operating frequencies 400 and $100 \mathrm{MHz}$ respectively (internal reference hexamethyldisiloxane). The solid-phase ${ }^{13} \mathrm{C}-\mathrm{NMR}$ spectra were obtained on a Bruker AM-500 spectrometer $(125 \mathrm{MHz})$ using a standard procedure utilizing cross polarization and magic angle spinning (CPMAS) technique (frequency $4.5 \mathrm{kHz}$; internal reference hexamethylbenzene). The tautomeric composition of obtained compounds was estimated by the integration of the appropriate signals in the ${ }^{1} \mathrm{H}$ NMR spectra. Elemental analysis of newly obtained compounds was carried out on a CHN Analyzer Hewlett Packard 185B. The purity of prepared compounds was checked by TLC on Silufol UV-254 plates, eluent butanol-water-acetone, 8:1:1.

Synthesis of aldoses 2-hydroxy- and 2-aminobenzoylhydrazones (1a-1j) and (2a-2d). To a solution of $0.01 \mathrm{~mol}$ of 2-hydroxybenzohydrazide or 2-aminobenzohydrazide in $25 \mathrm{ml}$ of methanol, $0.01 \mathrm{~mol}$ of an appropriate aldose was added, and the mixture was boiled for a period of $1-3 \mathrm{~h}$. The solvent was removed at a reduced pressure, the residue was washed with ether $(3 \times 50 \mathrm{ml})$, and the colorless crystalline substance was filtered off on a glass filter funnel $(40-100 \mu \mathrm{m})$, dried and stored in a desiccator over $\mathrm{P}_{2} \mathrm{O}_{5}$.

\subsection{L-Arabinose 2-Hydroxybenzoylhydrazone (1a)}

Yield $65 \%$, m.p. $191^{\circ} \mathrm{C}-192^{\circ} \mathrm{C}$ (lit. [3] m.p. $191^{\circ} \mathrm{C}$ ). ${ }^{1} \mathrm{H}-\mathrm{NMR}$ spectrum $\left(\operatorname{DMSO} d_{6}\right): \delta=$ form $\mathbf{A}(30 \%): 7.74(\mathrm{~d}$, 
$\mathrm{J}=4.4 \mathrm{~Hz}, \mathrm{HC}=\mathrm{N}$ ), 11.60 (br.s, NHCO), 12.11 (br.s, OH); form $\alpha-\mathbf{B}(20 \%): 10.22$ (br.s, NHCO), 12.50 (br.s, $\mathrm{OH}$ ); form $\beta$-B (25\%): 10.22 (br.s, NHCO), 12.20 (br.s, OH); form $\alpha-\mathbf{C}$ (25\%): 10.35 (br.s, NHCO), 11.96 (br.s, $\mathrm{OH})$ ppm. ${ }^{13} \mathrm{C}-\mathrm{NMR}$ spectrum $\left(\mathrm{DMSO}_{6}\right): \delta=$ form A: $63.88(\mathrm{C}-5), 65.52(\mathrm{C}-2), 70.29$ (C-3), $71.13(\mathrm{C}-4)$, $155.05(\mathrm{C}-1), 159.50($ ArC-O), $165.33(\mathrm{C}=\mathrm{O})$; form $\alpha-\mathrm{B}: 63.55(\mathrm{C}-5), 67.92(\mathrm{C}-4), 69.52(\mathrm{C}-3), 70.32(\mathrm{C}-2)$, 85.85 (C-1), 159.05 (ArC-O), $166.05(\mathrm{C}=\mathrm{O})$; form $\beta$-B: $65.30(\mathrm{C}-5), 69.01(\mathrm{C}-4), 72.35(\mathrm{C}-3), 73.65(\mathrm{C}-2)$, 90.80 (C-1), 159.31 (ArC-O), 166.65 (C=O); form $\alpha-\mathrm{C}: 61.83$ (C-5), 84.63 (C-4), 95.55 (C-1), 117.44 - 134.04 ( $\mathrm{Ar}$ in A-C) ppm. Found, \%: C 50.63; H 5.84; $\mathrm{N}$ 9.78. $\mathrm{C}_{12} \mathrm{H}_{16} \mathrm{~N}_{2} \mathrm{O}_{6}$. Calculated, \%: C 50.70; H 5.67; N 9.85.

\subsection{D-Glucose 2-Hydroxybenzoylhydrazone (1e)}

Yield $70 \%$, m.p. $196^{\circ} \mathrm{C}-198^{\circ} \mathrm{C}$ (lit. [3] m.p. $198^{\circ} \mathrm{C}$ ). ${ }^{1} \mathrm{H}-\mathrm{NMR}$ spectrum $\left(\mathrm{DMSO}_{6}\right): \delta=$ form $\mathbf{A}(5 \%): 7.76$ $(\mathrm{d}, \mathrm{J}=4.6 \mathrm{~Hz}, \mathrm{HC}=\mathrm{N}$ ), 11.60 (br.s, NHCO), 11.95 (br.s, OH); form $\alpha-\mathbf{B}(30 \%)$ ) 10.09 (br.s, NHCO), 12.00 (br.s, $\mathrm{OH}$ ); form $\beta$-B (65\%):10.22 (br.s, NHCO), 11.87 (br.s, OH) ppm. ${ }^{13} \mathrm{C}-\mathrm{NMR}$ spectrum (solid phase): $\delta=$ form $\beta$-B (100\%): 59.70 (C-6), 68.23 (C-4), 69.04 (C-2), 74.96 (C-5), 79.24 (C-3), 90.93 (C-1), 112.50, 118.91, 120.57, 128.66, $136.71(\mathrm{Ar}), 160.44(\mathrm{ArC}-\mathrm{O}), 172.12(\mathrm{C}=\mathrm{O}) \mathrm{ppm} .{ }^{13} \mathrm{C}-\mathrm{NMR}$ spectrum $\left(\mathrm{DMSO}_{6}\right): \delta=$ form $\mathbf{A}$ : 63.50 (C-6), 159.47 (ArC-O); form $\alpha$-B: 60.95 (C-6), 70.22 (C-4), 71.15 (C-5), 71.25 (C-2), 73.72 (C-3), 87.98 (C-1), $159.00($ ArC-O), $166.95(\mathrm{C}=\mathrm{O})$; form $\beta$-B: $61.42(\mathrm{C}-6), 70.50(\mathrm{C}-4), 71.55(\mathrm{C}-2), 76.85$ (C-5), 78.18 (C-3), 91.05 (C-1), 158.55 (ArC-O), 166.95 (C=O), 114.37-135.26 (Ar in $\mathbf{A}$ and $\mathbf{B})$ ppm. Found, \%: C 49.62; $\mathrm{H}$ 5.80; N 8.96. $\mathrm{C}_{13} \mathrm{H}_{18} \mathrm{~N}_{2} \mathrm{O}_{7}$. Calculated, \%: C 49.68; H 5.77; N 8.91.

\subsection{L-Arabinose 2-Aminobenzoylhydrazone (1g)}

Yield $75 \%$, m.p. $189^{\circ} \mathrm{C}-191^{\circ} \mathrm{C} .{ }^{13} \mathrm{C}-\mathrm{NMR}$ spectrum (DMSO $\left.d_{6}\right): \delta=$ form $\mathbf{A}(25 \%): 63.78(\mathrm{C}-5), 68.98(\mathrm{C}-2)$, 70.80 (C-3), 71.17 (C-4), $151.35(\mathrm{C}-1), 147.22(\mathrm{ArC}-\mathrm{N}), 165.69(\mathrm{C}=\mathrm{O})$; form $\beta$-B (65\%): 65.08 (C-5), 69.05 (C-4), $72.75(\mathrm{C}-3), 73.65(\mathrm{C}-2), 89.13(\mathrm{C}-1), 145.33(\mathrm{ArC}-\mathrm{N}), 168.74(\mathrm{C}=\mathrm{O})$; form $\alpha-\mathrm{C}(10 \%)$ : $61.82(\mathrm{C}-5)$, 76.89 (C-3), 78.81 (C-2), $85.53(\mathrm{C}-4), 95.94(\mathrm{C}-1), 145.80(\mathrm{ArC}-\mathrm{N}), 168.01(\mathrm{C}=\mathrm{O}), 114.67$ - 147.22 (Ar in A-C) ppm. Found, \%: C 57.71; H 5.76; N 13.39. $\mathrm{C}_{12} \mathrm{H}_{17} \mathrm{~N}_{3} \mathrm{O}_{5}$. Calculated, \%: C 57.67; H 5.81; N 13.45.

\subsection{L-Arabinose N-Methyl-N-(2-Aminobenzoyl)Hydrazone (2a)}

Yield $50 \%$, m.p. $168^{\circ} \mathrm{C}-171^{\circ} \mathrm{C} .{ }^{13} \mathrm{C}-\mathrm{NMR}$ spectrum $\left(\mathrm{DMSO} d_{6}\right): \delta=$ form $\mathbf{D}(65 \%): 38.35\left(\mathrm{CH}_{3}\right), 63.96(\mathrm{C}-5)$, 65.35 (C-2), 70.21 (C-3), $71.52(\mathrm{C}-4), 75.37(\mathrm{C}-1), 145.42(\operatorname{ArC}-\mathrm{N}), 172.33(\mathrm{C}=\mathrm{O})$; form $\mathbf{D}^{\prime}$ (35\%): 38.60 $\left(\mathrm{CH}_{3}\right), 63.75(\mathrm{C}-5), 65.35(\mathrm{C}-2), 70.30(\mathrm{C}-3), 71.52(\mathrm{C}-4), 76.88(\mathrm{C}-1), 145.50(\mathrm{ArC}-\mathrm{N}), 172.15(\mathrm{C}=\mathrm{O}), 117.65-$ 145.50 ( $\mathrm{Ar}$ in D and $\mathbf{D}^{\prime}$ ) ppm. Found, \%: C 52.59; H 6.50; N 14.06. $\mathrm{C}_{13} \mathrm{H}_{19} \mathrm{~N}_{3} \mathrm{O}_{5}$. Calculated, \%: C 52.52; H $6.44 ; \mathrm{N} 14.13$.

Spectral characteristics of compounds $1 \mathrm{~b}, 1 \mathrm{c}, 1 \mathrm{~d}, 1 \mathrm{f}$, and $2 \mathrm{~b}-2 \mathrm{~d}$ were described in works [6] [7].

\section{Acknowledgements}

This work received financial support from the Ministry of Education and Science of Russian Federation (contract 14.574.21.0002, No. RFMEFI57414X0002).

\section{References}

[1] El-Barbary, A.A., El-Ezz, A.Z.A., Sharaf, A.M. and Nielsen, C. (2006) The Synthesis of Some New Quinazolone Derivatives of Potential Biological Activity. Phosphorus, Sulfur, Silicon, 181, 1895-1912. http://dx.doi.org/10.1080/10426500500543834

[2] Majumdar, P., Pati, A., Patra, M., Behera, R.K. and Behera, A.K. (2012) Acid Hydrazides, Potent Reagents for Synthesis of Oxygen, Nitrogen, and/or Sulfur-Containing Heterocyclic Rings. Chemical Reviews, 114, 2942-2977. http://dx.doi.org/10.1021/cr300122t

[3] Kahl, R. (1904) Über die Paarung von Säurehydraziden mit Zuckerarten. Chemisches Zentralblatt, 75, 1493-1494.

[4] Gál, M., Tihanyi, E. and Dvortsák, P. (1986) Ring-Chain Tautomerism of Ortho-Aminosubstituted Aromatic Carboxylic Acid Hydrazones. I. Formation of 1,2,3,4-Tetrahydro-5H-1,3,4-Benzotriazepin-4-Ones. Acta Chimica Hungarica, 123, 55-61.

[5] Pihlaja, K., Simeonov, M.F. and Fülöp, F. (1997) Conformational Complexity in Seven-Membered Cyclic Triazepinone/Open Hydrazones. Part 1: 1-D and 2-D Variable Temperature NMR Study. Journal of Organic Chemistry, 62, 
5080-5088. http://dx.doi.org/10.1021/j0962322k

[6] Alekseev, V.V., Ershov, A.Y., Chernitsa, B.V., Doroshenko, V.A., Lagoda, I.V., Yakimovich, S.I., Zerova, I.V., Pakalnis, V.V. and Shamanin, V.V. (2010) Structure of Aldoses Condensation Products with 2-Hydroxy- and 2-SulfanylBenzohydrazides. Russian Journal of Organic Chemistry, 46, 860-865. http://dx.doi.org/10.1134/S1070428010060138

[7] Ershov, A.Y., Chernitsa, B.V., Doroshenko, V.A., Yakimovich, S.I., Alekseyev, V.V., Lagoda, I.V., Pakalnis, V.V., Zerova, I.V. and Shamanin, V.V. (2011) N-(2-Aminobenzoyl)-N-Methylhydrazones of Aldehydes and Aldoses and Their Cyclization to Benzo-1,3,4-Triazepine Derivatives. Chemistry of Heterocyclic Compounds, 46, 1486-1493. http://dx.doi.org/10.1007/s10593-011-0697-0

[8] Flegontov, S.A., Titova, Z.S., Stolyarov, A.P., Buzykin, B.I., Kitaev, Y.P. (1979) Hydrazones 62. The Structures of Aroylhydrazones with Intramolecular Hydrogen Bonding. Bulletin of the Academy of Sciences of the USSR Division of Chemical Science, 28, 948-953. http://dx.doi.org/10.1007/BF00963303 